\title{
OS USOS DA HISTÓRIA ORAL NO ESTUDO DO FUTEBOL: ETAPAS METODOLÓGICAS DE UMA EXPERIÊNCIA DE PESQUISA QUALITATIVA COM TORCIDAS ORGANIZADAS NA CIDADE DE SÃO PAULO
}

\author{
THE USES OF THE ORAL HISTORY IN THE FOOTBALL STUDY: \\ METHODOLOGICAL STAGES OF A QUALITATIVE RESEARCH \\ EXPERIENCE WITH ORGANIZED FAN GROUPS IN THE CITY OF SÃO \\ PAULO
}

\author{
Bernardo Borges Buarque de Hollanda*
}

\begin{abstract}
RESUMO
O artigo dá a conhecer uma experiência de pesquisa em história oral com torcidas organizadas de futebol na cidade de São Paulo. Com foco na metodologia de pesquisa, o propósito do texto é apresentar as etapas de construção de um processo de investigação junto a este segmento específico de torcedores no universo associativo do futebol profissional. Estigmatizadas pela opinião pública face a comportamentos antidesportivos, intenta-se adotar uma atitude compreensiva diante da problemática das torcidas organizadas, por meio da coleta de depoimentos de fundadores e lideranças dessas associações paulistanas entre 1960 e 2010. O suporte metodológico que fundamenta as cinquenta horas de histórias de vida - definição dos entrevistados, elaboração do roteiro, gravação das entrevistas, transcrição e edição dos depoimentos - permite não só a circunscrição de um material de análise seriado, a aprofundar o par conceitual história/memória, como enseja a proposição de um modelo passível de aplicação a outras regiões do país.
\end{abstract}

Palavras-chave: Futebol, história oral, metodologia, torcidas organizadas.

\begin{abstract}
The article presents a search experience in oral history with organized football supporters in the city of São Paulo, Brazil. Focusing on research methodology, the purpose of this study is to present the stages of constructing an investigation process with this specific segment of the associated universe of professional football. Stigmatized by public opinion in the face of unsportsmanlike conducts, the aim is to adopt an understanding attitude towards the issue of organized football supporters through the collection of testimonials of founders and leaderships of these associations between 1960 and 2010. The methodological support underlying the 50 hours of life stories - definition of respondents, preparation of the script, recording of interviews, transcription and editing of testimonials - allows not only circumscribing a serialized analysis material, deepening the conceptual history/ memory pair, but also enabling the proposition of a model capable of application to other regions of Brazil.
\end{abstract}

Keywords: Football, oral history, methodology, organized fan groups.

“Doutor em História Social da Cultura pela PUC-Rio (2008). Desde 2010, professor-pesquisador da Escola de Ciências Sociais da Fundação Getúlio Vargas (CPDOC-FGV). 


\section{INTRODUÇÃO}

O presente artigo tece proposições metodológicas sobre material levantado ao longo de doze meses de uma pesquisa social aplicada, de caráter qualitativo e quantitativo, realizada entre 2014 e 2015, sob os auspícios da FAPESP. Um duplo objetivo foi perseguido: quantitativamente, aplicar mais de seiscentos questionários aos torcedores uniformizados que frequentaram partidas de futebol válidas pelas competições esportivas oficiais, em nível estadual, nacional e internacional; qualitativamente, coletar mais de cinquenta horas de gravação de depoimentos audiovisuais junto a lideranças e fundadores de associações de torcedores na cidade de São Paulo, representativos dos seis clubes de futebol profissional em destaque Associação Portuguesa de Desportos, Clube Atlético Juventus, Santos Futebol Clube ${ }^{1}$, São Paulo Futebol Clube, Sociedade Esportiva Palmeiras e Sport Clube Corinthians Paulista.

Esse texto propõe uma primeira sistematização do material bruto coligido, a fim de fornecer ao leitor do presente dossiê, originado de um seminário internacional, um panorama do conjunto de atividades realizadas junto à coleta qualitativa das entrevistas, dando a conhecer o processo de gravação, transcrição e edição de depoimentos orais. Convém ressaltar que se tratou de um trabalho coletivo de construção do conhecimento, não apenas por envolver pesquisadores vinculados a duas instituições - o Centro de Pesquisa e Documentação de História Contemporânea do Brasil/CPDOC-FGV e o Centro de Referência do Futebol Brasileiro/CRFB-Museu do Futebol -, como pela própria dinâmica de interação com o objeto de pesquisa, no caso, integrantes, ex-integrantes, fundadores e líderes de torcidas organizadas de futebol.

A primeira frente de pesquisa - qualitativa -, aqui enfocada, permitiu aprofundar a relação conceitual história/memória (LE GOFF, 2003; CHAUÍ, 2000), por meio da reconstituição da trajetória de chefes e ex-chefes de grupos organizados de torcedores, com a reunião de uma série de informações e de versões consagradas acerca de diversos aspectos tratados nas entrevistas de História Oral.

\footnotetext{
${ }^{1}$ Ainda que sua sede se situe em outra cidade, boa parte de seus jogos ocorrem no estádio do Pacaembu. Além disto, a base de suas torcidas organizadas encontra-se localizada na capital paulistana, bem como muitos de seus seguidores. Por esta razão, o clube foi incluído e representado na amostra.
}

Dentre elas, vale elencar sete aspectos: 1 . As origens familiares e as lembranças da cidade por parte dos depoentes; 2. A constituição do vínculo com o bairro, com o futebol e com o clube; 3. A frequência aos estádios e a aproximação com os subgrupos de torcedores; 4. A rememoração de episódios consagrados da história do futebol profissional; 5. A maneira pela qual a identidade com a torcida organizada é construída discursivamente; 6 . A visão nativa sobre as brigas e o papel da violência no processo de constituição identitária; 7. As inter-relações estabelecidas com os diversos atores do mundo do futebol - dirigentes, torcedores, jornalistas, jogadores, técnicos e policiais.

A segunda frente da pesquisa - quantitativa versou sobre um amplo espectro de dados socioeconômicos e geográficos das associações de torcedores. As trinta e duas questões aplicadas por questionários permitiram um mapeamento bastante amplo de quem é o atual torcedor organizado, com a diferença de que, ao contrário das entrevistas quali, não se trata da cúpula nem de líderes das associações, mas dos integrantes "comuns" de TOs, compreendidos em termos de faixa etária, de proveniência de região da cidade e de posição na escala social, entre outros aspectos.

Além do perfil sociológico mais geral, diversos elementos da "cosmovisão" torcedora foram aferidas: graus de rivalidade interna e externa com outros torcedores e torcidas; frequência e participação nas caravanas; consumo de materiais e de produtos com a marca da torcida; acesso ou não à quadra e/ou à sede da torcida; nível de adesão formal e de vínculo com a facção, por meio do pagamento de mensalidades e formas de filiações afins; concordância com a participação e com o envolvimento da torcida com o carnaval paulistano; visão sobre as novas arenas, o encarecimento do preço dos ingressos e o processo de fidelização do torcedor proposto pelo clube, por meio do programa "sócio torcedor", entre outras questões polêmicas.

Acredita-se assim que a análise desse corpus de informações constitui uma fonte importante para a atualização do debate em torno de características comportamentais dos torcedores organizados na conjuntura que se seguiu à Copa do Mundo de futebol de 2014. Tal qual um retrato do Brasil pós-megaeventos, as narrativas coletadas e as estatísticas aferíveis atualizam quadros anteriormente realizados por outros 
colegas pesquisadores, referenciais na área, como Reis $(2009)^{2}$.

Além de insumo para outras pesquisas de cunho acadêmico, entende-se que os dados apresentados e as entrevistas realizadas podem contribuir para a discussão feita pelos meios de comunicação, bem como para a constituição de políticas públicas adequadas no tratamento preventivo de atos violentos premeditados por agrupamentos torcedores (MURAD, 2016).

$\mathrm{O}$ avanço acadêmico nas áreas da Sociologia e da Antropologia dos Esportes é notável nas últimas décadas no Brasil. Neste contexto, o presente artigo procura fornecer elementos para a construção de fontes orais e de instrumentos para o aprofundamento da temática. Dentre as contribuições, gostaríamos de salientar duas.

A primeira consiste na combinação entre uma pesquisa aplicada, de caráter quantitativo, e uma outra, de viés qualitativo. A formulação e o preenchimento de um total de seiscentos questionários, compostos por trinta e duas perguntas, permitem a cobertura de um conjunto bem amplo de questões relacionadas ao universo do futebol, ao pertencimento clubístico e aos valores associados às práticas e às representações dos torcedores organizados no Brasil, mais especificamente, aqueles residentes na cidade de São Paulo.

A forma de aplicação das enquetes também traz impactos positivos na construção do conhecimento científico, uma vez que se vale da pesquisa de campo e da interação direta com os associados às torcidas organizadas de futebol, no interior e nas adjacências de diversos estádios, bem como na sede de algumas associações de torcedores paulistanas.

O segundo contributo a ser destacado relaciona-se ao atingimento do objetivo primordial de uma pesquisa de sondagem pública, qual seja, traçar um perfil socioeconômico consistente do frequentador de estádios de futebol no Brasil contemporâneo, na sequência da realização dos megaeventos esportivos no país, de modo a avaliar a correlação entre a mudança fisionômica das praças esportivas brasileiras, especialmente aquelas situadas em São Paulo (BROCCHI, 2017), e a alteração do tipo de torcedor que passa a frequentar as partidas.

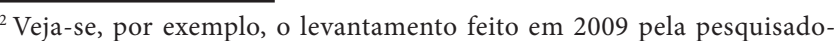
ra da UNICAMP, Heloísa Reis: http://revistagalileu.globo.com/Revista/ Common/0,EMI111936-17774,00-AS+TORCIDAS+ORGANIZADAS+N $\mathrm{AO}+\mathrm{SAO}+\mathrm{AS}+\mathrm{UNICAS}+\mathrm{CULPADAS} . \mathrm{html}$
}

Junto à caracterização de cunho econômico, social e antropológicos dos espectadores (BROMBERGER, 1998), os resultados alcançados facultam traçar igualmente um quadro da proveniência dos torcedores, com o mapeamento da origem dos mesmos, das zonas geográficas e dos bairros da cidade.

A pesquisa apresentada nesse artigo ambiciona igualmente uma contribuição para a área de recursos humanos especializados para a Academia. Consideramos para tanto a presença de uma equipe de pesquisa, formada por doze aplicadores e integrada por pesquisadores em diversos níveis - de graduandos a pós-graduandos e, destes, a professores doutores que participou de modo direto da coleta de campo nos estádios de futebol de São Paulo.

Mais do que um expediente burocrático de preenchimento de formulários, foram feitos treinamentos com os aplicadores, antes da ida a campo. Integrantes do órgão FGV-Opinião, especializados nas sondagens de opinião pública e na coleta de dados estatísticos, juntamente com membros do setor de pesquisa do Museu do Futebol, auxiliaram na condução de todo esse processo.

As incursões foram sucedidas de relatórios, em que os aplicadores narravam sua trajetória, circunstanciavam as peripécias de pesquisa e caracterizavam o perfil dos entrevistados naquele dia de jogo. Sendo assim, a pesquisa teve um cunho de construção eminentemente coletiva, em que se destacou o intercâmbio de experiências entre os coordenadores do projeto e os seus implementadores, em geral estudantes em fase de formação científica ou jovens recém-formados.

Como é sabido, as torcidas organizadas de futebol ocupam um lugar de estigmatização no imaginário social, na opinião pública e no jornalismo literário (BUFORD, 1992), de maneira geral. Vistos ora como "gangues" (ALMEIDA, 2006) ora como "galeras" (VIANNA, 1997), este lugar diz respeito à sua responsabilidade pela violência e ao seu protagonismo em condutas transgressoras, numa escala intergrupal juvenil, nas grandes cidades do país (MONTEIRO, 2003). Nos últimos anos, casos de homicídios ${ }^{3}$ agregaram-se

\footnotetext{
${ }^{3}$ A título de exemplo, leiam-se estas reportagens de portais brasileiros sobre confrontos fatais ocorridos em agosto de 2014 e março de 2017: http:// globoesporte.globo.com/sp/noticia/2014/08/torcidas-brigam-e-causam-confusao-antes-de-sao-paulo-x-santos.html; http://cidadeverde.com/morre-palmeirense-agredido-por-corintianos-em-briga-de-torcida-171143; http:// g1.globo.com/sao-paulo/noticia/fundador-da-mancha-verde-e-morto-na-zona-norte-de-sao-paulo-com-22-tiros.ghtml
} 
a tal imagem, tornando a situação ainda mais tensa e alarmante do ponto de vista normativo e penal-legal.

Em face dessa problemática, o texto aqui oferecido procura contribuir, senão para refutar tal imagem de senso-comum, ao menos para levantar e trazer um conjunto plural de informações e facetas acerca de tal perfil. Neste sentido, por diversos meios, quer seja do ponto de vista quantitativo, quer seja pelo viés qualitativo, ou mesmo pela produção de um filme-documentário de 30 minutos, intitulado "Territórios do torcer" e realizado pelo Núcleo Audiovisual do CPDOC, o conhecimento gerado almeja desdobramentos para a sua difusão e extensão.

Conforme frisado acima, tal difusão e extensão atingem o meio acadêmico, mas não se esgota no mesmo, projetando-se para além dele, com insumos para a compreensão de uma realidade que, sabemos, é complexa e multifacetada (TOLEDO, 2012).

Durante um ano de vigência da pesquisa (20142015), uma série de atividades foi desenvolvida, resultando em produtos inovadores e em iniciativas com potencialidades de se reverter em contribuições para a formulação de políticas públicas, atingindo os objetivos científicos almejando. Salientam-se dois deles.

O primeiro foi a produção aludida acima de um documentário de curta-metragem, com o título homônimo de "Territórios do Torcer". O mesmo foi composto de filmagens etnográficas colhidas na pesquisa de campo, de depoimentos colhidos com lideranças, em um total de 50 horas, e de imagens do acervo pessoal desses entrevistados. O filme foi exibido em salas de aula e em eventos acadêmicos como o I Seminário Internacional Interdisciplinar de Estudos sobre Futebol e Sociedade, realizado em 20 e 21 de junho de 2017 na Universidade Estadual de Ponta Grossa (UEPG), proporcionando debates com pesquisadores e com o público presente à sessão audiovisual.

Outro aspecto que merece realce é a interlocução estabelecida não apenas com torcedores organizados, através de sua associação nacional (ANATORG), como também com autoridades públicas, policiais civis e militares, jornalistas esportivos e representantes da secretaria de esporte do Estado. O diálogo foi possível graças à iniciativa de realização de simpósios e de seminários, nacionais e internacionais, como o ocorrido em maio de 2014, na FGV, intitulado "Brasil-França: intercâmbios acadêmicos nos estudos do futebol", que contou com a presença de especialistas franceses no estudo do hooliganismo.

Esses debates públicos permitiram que os conhecimentos gerados pela pesquisa pudessem ecoar para além da esfera universitária, sendo pauta para programas de rádio, TV e jornal, ao longo desse período, com base nas expectativas geradas pela realização do XX Mundial FIFA de futebol no Brasil.

\section{OS DEPOIMENTOS}

"A busca pela reminiscência autêntica, à margem
da corrosão temporal, é uma quimera, toda recor-
dação contém uma relativa arbitrariedade no seu
rearranjo, o presente é um fator dinâmico, intrín-
seco ao processo mnemônico".

Renato Ortiz (2010, p. 12)

Para a gravação das entrevistas, o contato com os torcedores, na grande maioria das vezes, ficou a cargo de um estagiário de pesquisa e de representantes do Museu do Futebol. Após o levantamento dos nomes, alguns deles feitos graças à internet e às redes sociais, a abordagem era feita por ligação telefônica, por endereço eletrônico ou pessoalmente.

Houve vezes em que informantes, ligados às torcidas, ajudaram no estabelecimento de uma intermediação. Em determinadas ocasiões, um entrevistado mencionava outro potencial entrevistável e colaborava na indicação dele, fornecendo-nos o telefone ou o e-mail. Visitas prévias da equipe do Museu do Futebol às sedes de torcidas foram decisivas para aproximar e para contatar determinadas lideranças.

Dessa maneira, o caráter serial das entrevistas foi definido em torno dos torcedores pertencentes às gerações que atuaram majoritariamente na fundação das associações de torcidas entre o final dos anos 1960 e 1970. A partir dessa sistematização cronológica, avançou-se até o presente decênio. Nem sempre foi possível seguir de maneira estrita a cronologia, mas a série ao final foi completada.

Com uma média de duas horas de duração por depoimento, alcançou-se o total estimado de quarenta horas de testemunhos, transcritas e editadas. Vale dizer que a meta de entrevistas foi ultrapassada, chegando-se a quase 50 horas de gravação.

Decorrência das inevitáveis vicissitudes de cada entrevista, houve aquelas que ultrapassaram a marca 
das quatro horas de duração, como a de Vila Maria, fundador do grêmio Camisa 12, do Corinthians, fundado em 1971, último convidado a ceder depoimento.

Em contrapartida, noutras gravações, ainda que poucas, as entrevistas não chegaram a atingir uma hora e meia, devido à característica mais contida de seu entrevistado. Este foi o caso de André Azevedo, líder da Dragões da Real e presidente da ANATORG - Associação Nacional de Torcidas Organizadas. Isto também se deu com Márcia, da Gaviões, visivelmente tímida e incomodada com a câmara de gravação. No total, foram vinte e duas gravações.

Assim, embora as entrevistas de História Oral (FERREIRA; AMADO, 2002) procurem a profundidade e a larga duração, isto nem sempre foi possível, quer seja por incompreensão dos depoentes quer seja por falta de tempo. Por mais que as finalidades da pesquisa fossem explicitadas aos torcedores, havia aqueles que associavam a gravação de sua fala à de uma edição destinada para uma emissora de televisão, como aconteceu com Danilo Zamboni, fundador da Torcida Independente (1972).

Com efeito, o entrevistado preferia não se alongar na filmagem e abreviava passagens consideradas importantes pelos entrevistadores (infância, composição familiar, divisões de base, etc.). Isto, por exemplo, ocorreu na entrevista dada por Marcelo Lima, presidente da TUP - Torcida Uniformizada do Palmeiras.

Deve-se frisar que determinados torcedores até se predispuseram a falar, mas em função de uma série de contratempos pessoais e profissionais, acabaram não o fazendo, como se deu com Erika Papangelacos, relações públicas dos Gaviões da Fiel. Alguns simplesmente relutaram, sem responder ao convite. Outros aceitaram e, mesmo depois de marcar a gravação, não compareceram, conforme ocorrido com Antônio Baccic, fundador da TUP (1970).

Tal ausência aconteceu mesmo quando deixávamos o entrevistado à vontade para definir o local de entrevista. O lugar principal para gravar foi o Auditório Armando Nogueira, do Museu do Futebol, mas também se utilizou das sedes das torcidas, como no caso de Tomate, presidente da Escola de Samba Dragões da Real, ou mesmo no escritório de trabalho do torcedor, conforme sucedeu com Adamastor, ex-presidente da Independente.

Uma vez apresentado esse quadro geral do conjunto dos depoentes, segue-se o quadro geral de concessão de entrevistas e o quanto se distou e/ou se aproximou da totalidade estimada. Com o início das gravações em setembro de 2014 e com o seu término em março de 2015, perfazendo um intervalo de seis meses, considera-se, para tanto, o número total de vinte e dois torcedores e as datas das respectivas entrevistas realizadas.

Quadro 1 - Entrevistas

\begin{tabular}{|c|c|c|}
\hline Torcida & Nome/Posição & $\begin{array}{l}\text { Data da } \\
\text { Entrevista }\end{array}$ \\
\hline Camisa 12 & Vila Maria (fundador) & $09 / 03 / 2015$ \\
\hline Caju (Juventus) & Sérgio Agarelli & $06 / 02 / 2015$ \\
\hline Dragões da Real & $\begin{array}{l}\text { André Azevedo } \\
\text { (presidente atual) }\end{array}$ & $18 / 09 / 2014$ \\
\hline Dragões da Real & $\begin{array}{l}\text { Tomate (presidente da } \\
\text { Escola de Samba) }\end{array}$ & $15 / 10 / 2014$ \\
\hline Estopim da Fiel & Bambu (presidente) & $17 / 12 / 2014$ \\
\hline Gaviões da Fiel & $\begin{array}{l}\text { Chico } \\
\text { Malfitani(fundador) }\end{array}$ & $31 / 10 / 2014$ \\
\hline Gaviões da Fiel & $\begin{array}{l}\text { Dentinho (ex- } \\
\text { presidente) }\end{array}$ & $05 / 02 / 2015$ \\
\hline Gaviões da Fiel & $\begin{array}{l}\text { Márcia (torcedora- } \\
\text { símbolo) }\end{array}$ & $11 / 02 / 2015$ \\
\hline Gaviões da Fiel & Minduim (liderança) & $31 / 10 / 2014$ \\
\hline Gaviões da Fiel & Paracatá (liderança) & $14 / 10 / 2011$ \\
\hline Gaviões da Fiel & Pulguinha (liderança) & $10 / 02 / 2015$ \\
\hline Leões da Fabulosa & $\begin{array}{l}\text { Beto (liderança dos } \\
\text { anos 1970) }\end{array}$ & $13 / 02 / 2015$ \\
\hline Independente & $\begin{array}{l}\text { Adamastor (ex- } \\
\text { presidente) }\end{array}$ & $17 / 11 / 2014$ \\
\hline Independente & $\begin{array}{l}\text { Danilo Zamboni } \\
\text { (fundador) }\end{array}$ & $13 / 11 / 2014$ \\
\hline Mancha Verde & Jânio (liderança) & $16 / 12 / 2014$ \\
\hline Mancha Verde & $\begin{array}{l}\text { Serdan (presidente da } \\
\text { Escola de Samba) }\end{array}$ & $19 / 01 / 2015$ \\
\hline $\begin{array}{l}\text { Sangue Jovem do } \\
\text { Santos }\end{array}$ & $\begin{array}{l}\text { Alexandre Cruz } \\
\text { (liderança atual) }\end{array}$ & $16 / 01 / 2015$ \\
\hline Savóia & $\begin{array}{l}\text { Camilo (liderança } \\
\text { atual) }\end{array}$ & $18 / 12 / 2014$ \\
\hline $\begin{array}{l}\text { Torcida Jovem do } \\
\text { Santos }\end{array}$ & Cosme (fundador) & $\begin{array}{l}29 / 10 / 2011 \\
\text { (piloto) }\end{array}$ \\
\hline TUP & Marcelo (presidente) & $28 / 01 / 2015$ \\
\hline TUP & $\begin{array}{l}\text { Matheus Rodak (ex- } \\
\text { presidente) }\end{array}$ & $09 / 09 / 2014$ \\
\hline TUSP & $\begin{array}{l}\text { Hélio Silva (ex- } \\
\text { presidente) }\end{array}$ & $11 / 02 / 2015$ \\
\hline
\end{tabular}

Fonte: dados do autor. 
As descrições acima, e os respectivos dados supracitados, evidenciam o empenho e o desempenho dos pesquisadores no decurso de doze meses. As diferentes reações de cada um dos torcedores constituíram um indicativo importante da percepção dos mesmos acerca do objetivo da pesquisa e do seu papel na constituição do acervo do Museu do Futebol.

Graças a tal intermediação, todos os torcedores se dispuseram a falar sem a cobrança de honorários ou qualquer tipo de contraprestação financeira por parte das instituições. Ademais, não houve quaisquer obstáculos para gravar depoimento sem que se deixasse de assinar a Carta de Cessão, fundamental para a "publicização" dos resultados.

\section{A CONSTRUÇÃO DO ROTEIRO}

Uma das primeiras atividades realizadas no quadro de uma pesquisa de História Oral (ALBERTI, 2004) é a definição do Roteiro de Entrevista. Este consiste no passo primordial da pesquisa. Com base nele, a elaboração e a formulação das questões que norteavam a preocupação central dos pesquisadores poderiam vir a ser estruturadas.

O delineamento de um guia geral de perguntas procurou seguir a tradição metodológica da experiência do CPDOC com fontes orais. Para tanto, adotou-se o método das histórias de vida, em que o Roteiro é montado de modo a permitir um mínimo encadeamento cronológico na rememoração dos fatos. Longe de ser uma camisa de força, o que seria um contrassenso metodológico, a biografia do entrevistado é percorrida deixando-se o próprio à vontade para recontar suas recordações segundo seu fluxo de memória.

A estrutura das histórias biográficas, acionadas retrospectivamente, foi combinada ao formato de uma entrevista de cunho temático, uma vez que o foco da investigação tem por tema a rememoração da atuação dos torcedores nas arquibancadas e em suas respectivas torcidas. Nesta primeira fase da pesquisa quali, seguiu-se, pois, a metodologia da História Oral, que se orienta em torno das "histórias de vida" e das "histórias temáticas". Estas requerem uma estruturação tripartite, assim sequenciada: 1 . A preparação da entrevista, com o levantamento de informações e a montagem do Roteiro; 2. A gravação do depoimento, filmada e gravada em áudio, como backup; 3 . A transcrição, a conferência de fidelidade, a análise do material colhido e o posterior arquivamento.

O roteiro de entrevista foi montado de acordo com as premissas metodológicas das fontes orais, acima citadas, cujo cerne são as histórias de vida. Ao contrário das figuras públicas, notoriamente conhecidas e cujas informações circulam nos periódicos e nas demais empresas de comunicação privadas de circulação, no caso das lideranças das TOs as notícias disponíveis são escassas e pontuais. Ainda assim coube ao estagiário Raphael Piva, mestrando em antropologia social pela USP, as buscas para localizar informações e dados sobre as Torcidas Organizadas na mídia eletrônica.

Esse fato acarretou a adoção de um novo expediente para montar o roteiro. O fio condutor das perguntas seguiu um traçado que teve de ser mais genérico e abstrato. Por suposto, as questões de fundo interessavam à pesquisa, mas careciam de dados mais específicos relativos aos entrevistados. Outrossim, o Roteiro estruturou-se com cerca de cinquenta perguntas formuladas, tal como exemplificado a seguir.

Após o contato, o agendamento e a preparação do roteiro referente ao entrevistado, compartilhado pela equipe de pesquisa, a segunda etapa consistiu na gravação do depoimento. Sempre que possível, dentro de uma negociação com o depoente, acordou-se a realização da entrevista no Auditório do Museu, acondicionado e climatizado para a filmagem. Segundo a recomendação do Manual de história oral, elaborado pela historiadora Verena Alberti (2012), deve-se restringir o número de entrevistadores, de modo a favorecer a criação de um ambiente de reserva e intimidade no momento da gravação.

A seguir, reproduz-se o primeiro modelo do Roteiro de Entrevista elaborado pela equipe do CPDOC, e debatido conjuntamente com os integrantes do Museu do Futebol. Composto por cinquenta questões, e subdividido em sete partes, seu intento era enfeixar um primeiro conjunto de indagações, passíveis de aplicação, em princípio, para todo e qualquer depoente, com as nuances matizadas segunda cada entrevistado, seu respectivo clube e torcida: 


\section{Roteiro Semiestruturado de Entrevista: 50 Questões - Torcida Gaviões da Fiel}

$1^{\text {a }}$ Parte: Infầncia e Primeiras Lembranças do Futebol

Nome completo, data e local de nascimento.

Conte sobre sua família, seus pais, seus avós, o trabalho deles.

Fale sobre suas lembranças de infầncia, sobre o lugar onde cresceu, os amigos, o bairro.

Estudou? Onde? Até quando? Trabalhava ou ajudava os pais quando garoto? Em quê?

Como se interessou por futebol? Alguém o influenciou?

Qual é a sua lembrança mais antiga do futebol?

\section{$2^{a}$ Parte: Frequência aos Estádios}

Quando você começou a frequentar estádios?

Quais estádios e com que frequência?

Com quem você ia? Você se lembra destes primeiros jogos?

Quais são suas lembranças da torcida do Corinthians nesses primeiros jogos?

Qual foi o primeiro título do Corinthians que você viu?

Alguma história desse período inicial nos estádios te marcou?

Quando você começou a ir ao estádio sozinho ou com amigos, sem ser acompanhado por uma pessoa mais velha / responsável?

Quem eram esses amigos? Da onde você os conhecia?

\section{$3^{\text {a }}$ Parte: A Torcida}

Como e quando que você começou a se envolver com os Gaviões da Fiel?

Conte um pouco sobre o início de sua trajetória dentro dos Gaviões.

Qual foi o primeiro departamento/função que você teve dentro da torcida?

Como que era conciliar sua vida familiar e de trabalho com a vida de torcedor organizado?

Você se lembra de sua primeira caravana com os Gaviões? Conte um pouco sobre como foi essa experiência.

Você vivenciou o período da Democracia Corintiana como membro dos Gaviões? Conte sobre suas lembranças desse período e da relação dos Gaviões com o movimento dos jogadores corintianos.

Você participou da movimentação pela redemocratização do país como membro dos Gaviões da Fiel? Conte sobre suas lembranças desse período e da relação dos Gaviões com esse momento histórico do Brasil.

O Corinthians conquistou muitos títulos na década de 1990. Algum momento dessa época, jogo e/ou caravana, te marcou como membro dos Gaviões?

Em 2000, o Corinthians conquistou o Mundial de Clubes da Fifa. Você esteve presente nos jogos no Morumbi? Viajou até o Maracanã para a final? Conte um pouco da experiência dessa caravana.

Entre a década de 1990 até meados da década de 2000, existiram diversas parcerias que conduziram o futebol do Corinthians. Desde o Banco Excel, passando pelas Hicks Mouse, até a MSI, foram momentos que alternaram a conquista de grandes títulos e de várias turbulências que atravessavam a relação entre diretoria, elenco de jogadores e torcida. Como era a relação dos Gaviões com essas parcerias?

Como os Gaviões agiam no dia a dia da política do clube nesse período?

Em 2007, o Corinthians foi rebaixado para a série B do Campeonato Brasileiro. O que significou esse momento para você? Você esteve na caravana do jogo contra o Grêmio, para Porto Alegre, que confirmou o descenso do Corinthians? Pode contar um pouco suas lembranças desse dia?

No mesmo ano, após uma movimentação intensa das torcidas corintianas, o ex presidente Alberto Dualib saiu do cargo que ocupava desde 1993. Como foi essa mobilização organizada pelos torcedores? Você esteve envolvido? Pode contar sobre sua experiência dentro desse movimento? 
Ainda nesse ano, o Andrés Sanchez foi eleito novo presidente do clube. Qual foi o significado de ter um presidente que começou em uma torcida organizada?

Em 2012, o Corinthians quebra o tabu e conquistou a Copa Libertadores da América. Você vivenciou como torcedor organizado as participações anteriores do clube na Libertadores, principalmente as duas eliminações para o rival Palmeiras em 1999 e 2000? Conte um pouco sobre essas experiências anteriores da torcida corinthiana com a Libertadores.

Você esteve presente na conquista do Mundial de 2012 no Japão? Conte sobre essa experiência.

\section{4 a Parte: Crescimento das Torcidas Organizadas e Violência}

Em 1995, acontece a "Batalha do Pacaembu", em um jogo entre São Paulo e Palmeiras, que é um grande marco na história das torcidas organizadas no Brasil. As torcidas foram incessantemente perseguidas pelo estado e pela opinião pública. Quais são as suas lembranças desse período?

Existia, nessa época, um diálogo entre as torcidas de diferentes clubes a respeito do crescimento da violência e das imagens negativas que eram atribuídos aos torcedores organizados pela opinião pública?

Além das punições e proibições, quais foram às outras consequências que você sentiu no dia a dia como frequentador de estádios e/ou membro de torcida organizada?

Após o fato, o que a sua família e as pessoas que conviviam com você passaram a falar sobre frequentar estádios e ser membro de uma torcida organizada?

\section{Parte: A Torcida e o Carnaval}

Você fez parte do bloco carnavalesco dos Gaviões da Fiel? Conte sobre como eram os desfiles e a organização desse bloco.

Você esteve presente no processo de transformação do bloco carnavalesco em escola de samba? Conte sobre as razões e motivações que levaram os Gaviões a se tornar uma escola de samba.

Como os Gaviões foram recebidos pelas outras escolas de samba? Houve muito preconceito e resistência por se tratar de uma torcida organizada?

Em 1995, os Gaviões conquistaram seu primeiro título do grupo especial do carnaval de São Paulo. Você já esteve envolvido, de alguma maneira, seja desfilando ou ocupando alguma outra função, na parte da escola de samba? Você se lembra do que representou esse título de 1995 ?

Como é a divisão e a relação que surge dessa dupla missão de ser tanto uma torcida organizada como uma escola de samba? Quais as dificuldades, conflitos em conciliar as duas atividades?

Após tantos anos desfilando na elite do carnaval de São Paulo, você acha que mudou a visão que as outras escolas de samba de São Paulo tinham dos Gaviões?

\section{$6^{\text {a }}$ Parte: Articulação entre Torcidas Organizadas}

Você esteve envolvido em algum movimento / tentativa de articulação política entre torcidas organizadas de diferentes clubes? Conte sobre essas experiências e quais as dificuldades em se conseguir isso.

Olhando o atual momento das torcidas organizadas, bem como sua trajetória, você vê alguma importância nessa articulação e diálogo entre torcidas rivais?

\section{$7^{\text {a }}$ Parte: As Transformações dos Estádios e o Novo Perfil dos Torcedores}

Como você vê a torcida corinthiana, no geral, desde que começou a frequentar estádios até os dias atuais? Você percebe alguma transformação em relação ao perfil desses torcedores?

E quanto a composição interna dos Gaviões? Desde que você frequenta a torcida quais foram às transformações por qual ela passou em relação ao perfil de seus associados? 
Existiam muitas mulheres que faziam parte da torcida? Elas participam mais do cotidiano da torcida hoje em dia em comparação a época em que começou a frequentar os Gaviões?

De uma maneira geral, os torcedores "comuns" do Corinthians sempre nutriram um sentimento muito positivo pelos Gaviões da Fiel, diferentemente do que ocorria em outros clubes. Como você acha que é essa relação atualmente?

Nos últimos anos, seguindo uma tendência mundial, tem se acentuado um processo de drásticas transformações nos estádios brasileiros. Esse é justamente o momento em que o Corinthians passa a ter o seu próprio estádio, localizado em Itaquera. O que significa a "Arena Corinthians" pra você?

Tendo passado, agora, mais de 6 meses da final da Copa do Mundo no Brasil, você consegue sentir alguma diferença na rotina das torcidas organizadas nos estádios? Em que direção vai essas diferenças?

Como você avalia o momento atual dos estádios brasileiros e quais são as suas expectativas para o futuro?

Os Gaviões da Fiel sempre se caracterizaram como uma torcida muito atuante na vida política do Corinthians.

Como você vê a atuação dos Gaviões e das outras torcidas organizadas do Corinthians frente ao cenário político atual do clube?

Esse questionário, ainda bastante genérico, conquanto já direcionado a um representante de torcida e de clube específicos, intentou esquadrinhar as etapas mais evidentes da trajetória do atleta, com a obtenção de dados gerais quanto a aspectos socioeconômicos e socioculturais, seguido de seu ingresso no ambiente dos estádios e o início da trajetória na torcida. Deste, chegava-se ao tema incontornável - a "violência" entre os "clubes de torcedores" (Flores, 1995; Fernandes, 2000).

Na sequência, abordava-se a vida clubística e o nível de envolvimento com a política interna dos clubes, além de explorar a temática das viagens e das caravanas nos jogos como visitante, em partidas "fora de casa". Cerra-se a gravação com uma avaliação de ordem mais ampla sobre o significado das novas arenas no que tange à "festa" - categoria nativa - nas arquibancadas e às limitações do ato de torcer na contemporaneidade.

Para essa confecção, seguiu-se o postulado do historiador José Carlos Sebe Bom Meihy: "Nas entrevistas de história oral de vida, as perguntas devem ser amplas, sempre postas em grandes blocos, de forma a indicar os grandes acontecimentos". (2000, p. 62)

O Roteiro, abaixo parcialmente reproduzido, foi aplicado em consonância com um segundo modelo de questão, direcionado especificamente para cada um dos entrevistados selecionados. O itinerário das perguntas também se baseou em um padrão preexistente no CPDOC e procurou estipular, por meio de uma tabela, três tipos de informação recorrentes. $\mathrm{Na}$ vertical, temos três variáveis: $1^{\mathrm{a}}$ ) Ano; $2^{\mathrm{a}}$ ) Dados informativos da conjuntura histórica; $3^{\text {a }}$ ) Informações biográficas do entrevistado. Na horizontal, as lacunas são preenchidas segundo cada torcedor. 
Quadro 2 - Roteiro

\begin{tabular}{|c|c|c|}
\hline$\stackrel{?}{\Xi}$ & Conjuntura histórica & Informações biográficas \\
\hline & $\begin{array}{l}\text { - 1993: o Palmeiras quebra o jejum de } 17 \text { anos sem } \\
\text { títulos, vencendo o campeonato paulista contra } \\
\text { o rival Corinthians, dando inicio a uma década } \\
\text { vitoriosa dentro de campo. } \\
\text { Títulos nessa década: } \\
\text { Copa Libertadores da América: 1999; } \\
\text { Copa Mercosul: } 1998 \text {; } \\
\text { Campeonato Brasileiro: 1993, 1994; } \\
\text { Copa do Brasil: } 1998 \text {; } \\
\text { Torneio Rio-São Paulo: 1993; } \\
\text { Campeonato Paulista: } 1993 \text {, 1994, 1996. } \\
\text { Técnicos vitoriosos do clube no período: } \\
\text { Vanderlei Luxemburgo: (1993) - Campeão do } \\
\text { Campeonato Paulista, do Torneio Rio-São Paulo e } \\
\text { do Campeonato Brasileiro } \\
\text { (1994) - Campeão do Campeonato Paulista e do } \\
\text { Campeonato Brasileiro } \\
\text { (1996) - Campeão da Copa Euro-América e do } \\
\text { Campeonato Paulista } \\
\text { Luiz Felipe Scolari: } \\
\text { (1997) Campeão da Taça Maria Quitéria e do Troféu } \\
\text { Naranja } \\
\text { (1998) Campeão da Copa do Brasil e da Copa } \\
\text { Mercosul } \\
\text { (1999) Campeão da Copa Libertadores da América } \\
\text { - A Sociedade Esportiva Palmeiras é intitulada o } \\
\text { “Campeão do Século XX”, sendo considerada, em } \\
\text { rankings de diferentes instituições e veículos da } \\
\text { mídia, a equipe brasileira mais vitoriosa do século } \\
\text { XX. } \\
\text { - Os presidentes do clube nessa década foram: } \\
\text { Carlos Bernardo Facchina Nunes, que ficou no } \\
\text { comando do Palmeiras até 1992 e foi o responsável } \\
\text { pela assinatura do primeiro contrato de co-gestão do } \\
\text { futebol brasileiro (Palmeiras-Parmalat); e Mustafá } \\
\text { Contursi Goffar Majzoub, que permaneceu na } \\
\text { preside clube entre 1993 e 2004. }\end{array}$ & 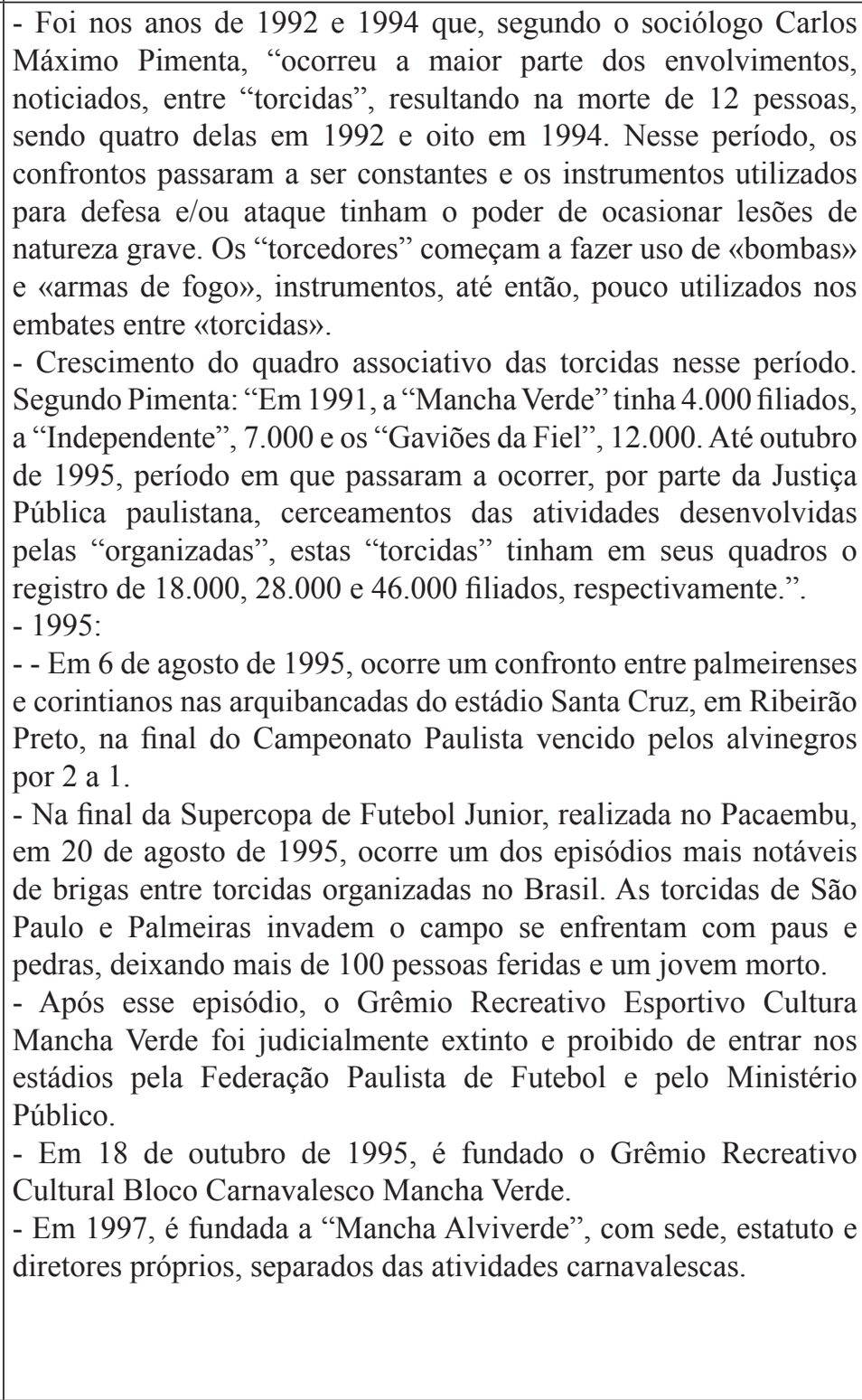 \\
\hline
\end{tabular}


continuação

\begin{tabular}{|c|c|c|}
\hline$\stackrel{?}{\Xi}$ & Conjuntura histórica & Informações biográficas \\
\hline & $\begin{array}{l}\text { - 2002: o Palmeiras é rebaixado pela primeira vez } \\
\text { para a segunda divisão do campeonato brasileiro. } \\
\text { Títulos conquistados na década: } \\
\text { Campeonato Paulista: 2008; } \\
\text { Copa dos Campeões: 2000; } \\
\text { Torneio Rio-São Paulo: 2000. } \\
\text { Técnicos vitoriosos do clube no período: } \\
\text { Luiz Felipe Scolari: (2000) Torneio Rio-São Paulo; } \\
\text { Murtosa: (2000) Campeão da Copa dos Campeões; } \\
\text { Jair Picerni: (2003) Campeonato Brasileiro Série B; } \\
\text { Vanderlei Luxemburgo: (2008) - Campeonato } \\
\text { Paulista. } \\
\text { - Após o final do mandato de Mustafá, em 2004, } \\
\text { Affonso Della Monica Netto assume a presidência } \\
\text { do clube até 2008. Além do título de Campeão } \\
\text { Paulista de 2008, outros feitos durante a sua gestão } \\
\text { foram: a aprovação do projeto da Arena Palestra } \\
\text { Itália, a modernização do clube social, Academia } \\
\text { de Futebol e do estádio Palestra Itália, a criação } \\
\text { do Espaço Visa no setor de arquibancadas, nova } \\
\text { iluminação do Palestra Itália, instituição de urnas } \\
\text { eletrônicas nas eleições oficiais, reformas gerais } \\
\text { no clube de campo, reformas gerais na Academia } \\
\text { 2, novas salas de imprensa na Academia e estádio } \\
\text { Palestra Itália. } \\
\text { - Entre 2009 e 2010, Luiz Gonzaga de Mello } \\
\text { Belluzzo, economista consagrado, assume a } \\
\text { presidência do clube. Durante a sua gestão se } \\
\text { iniciam as obras da Arena Palestra Itália. }\end{array}$ & 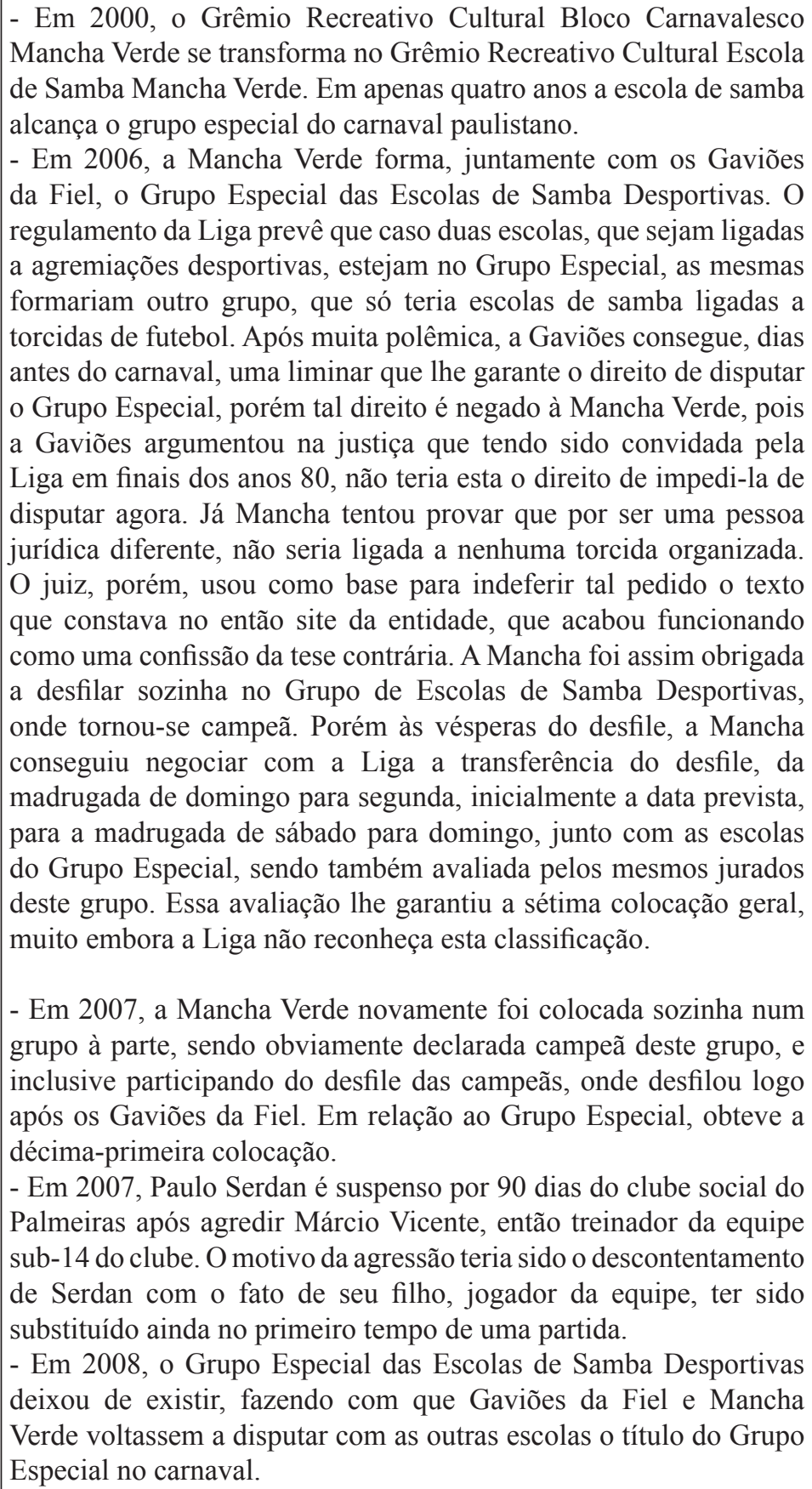 \\
\hline
\end{tabular}

continua 
continuação

\begin{tabular}{|c|c|c|}
\hline$\stackrel{?}{=}$ & Conjuntura histórica & Informações biográficas \\
\hline 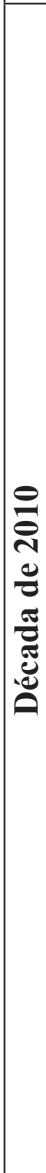 & $\begin{array}{l}\text { - Em 2010, Salvador Hugo Palaia assumiu a } \\
\text { presidência do clube. } \\
\text { - Em 2011, Arnaldo Luiz Albuquerque Tirone } \\
\text { assumiu a presidência do clube } \\
\text { - Em 2012, o Palmeiras conquistou a Copa do Brasil, } \\
\text { sob o comando do técnico Luiz Felipe Scolari. } \\
\text { - Ainda em 2012, o Palmeiras voltou a ser rebaixado } \\
\text { para a série B do campeonato brasileiro. } \\
\text { - Em 2013, Paulo de Almeida Nobre assumiu a } \\
\text { presidência do clube. } \\
\text { - Em 2014, o Palmeiras comemora o seu centenário. } \\
\text { O novo estádio do clube, nomeada Arena Allianz } \\
\text { Parque, foi inaugurada oficialmente em } 19 \text { de } \\
\text { novembro de } 2014 \text {, na derrota por } 2 \text { a } 0 \text { para o Sport } \\
\text { de Recife. }\end{array}$ & $\begin{array}{l}\text { - Em 2010, a Escola de Samba Mancha Verde alcança a quarta } \\
\text { colocação na divisão especial do carnaval, ficando apenas um ponto } \\
\text { da campeã Rosas de Ouro. } \\
\text { - Em 2011, a torcida Mancha Alviverde foi proibida formalmente } \\
\text { de frequentar os estádios (entrar com material que identificasse a } \\
\text { torcida), durante } 6 \text { meses, por conta de um episódio que ocorreu em } \\
\text { Presidente Prudente, onde o Palmeiras enfrentou o rival Corinthians. } \\
\text { Na ocasião, em uma confusão entre as torcidas das duas equipes, dois } \\
\text { torcedores palmeirenses foram baleados. A Polícia Militar enviou } \\
\text { um relatório a Federação Paulista de Futebol responsabilizando a } \\
\text { Mancha Alviverde pelo ocorrido. } \\
\text { - Em } 25 \text { de março de } 2012 \text {, dois integrantes da Mancha Alviverde, } \\
\text { André Alves Lezo, de } 21 \text { anos, e Guilherme Vinícius Jovanelli } \\
\text { Moreira, de } 19 \text { anos, morreram após confronto com torcidas do } \\
\text { Corinthians, na Avenida Inajár de Souza, horas antes do clássico } \\
\text { entre as duas equipes. A briga teria sido uma revanche de um } \\
\text { episódio ocorrido em agosto do ano interior, onde o corintiano } \\
\text { e membro dos Gaviões da Fiel, Douglas Karin Silva, foi achado } \\
\text { morto no rio Tiête após briga de torcidas. } \\
\text { - A Mancha Alviverde pagou os custos do enterro do torcedor André } \\
\text { Lezo e comprou três jazigos no cemitério do Jaraguá, zona norte } \\
\text { de São Paulo. Segundo Marcos Ferreira, presidente da entidade, o } \\
\text { preço entre comprar um ou três túmulos não variava muito. } \\
\text { - Em entrevista sobre a violência das torcidas para o jornal Folha de } \\
\text { São Paulo, Paulo Serdan, entre outras coisas, afirmou sua influência } \\
\text { no futebol palmeirense: "Do time do Palmeiras que disputou a } \\
\text { última Copa São Paulo, entre titulares e reservas coloquei uns sete } \\
\text { ou oito jogadores". }\end{array}$ \\
\hline 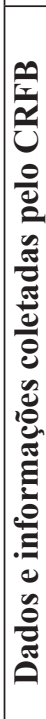 & & $\begin{array}{l}\text { - Em visita à sede da torcida Mancha Alviverde, em } 8 \text { de março de } \\
\text { 2012, os pesquisadores do CRFB levantaram os seguintes dados e } \\
\text { informações: } \\
\text { - O número de sócios da torcida, após o recadastramento feito por } \\
\text { conta da extinção da antiga Mancha Verde e do surgimento da } \\
\text { Mancha Alviverde, beirava os } 25 \text { mil até a data de visita do CRFB. } \\
\text { - Sobre o perfil dos associados da torcida, Marcos Ferreira, } \\
\text { presidente da torcida desde } 2012 \text {, afirmou que convivem na torcida } \\
\text { "de juízes de direito a catadores de papel; pessoas que moram em } \\
\text { Alphaville ou em um barraco de madeira". Embora, o perfil da } \\
\text { maioria das pessoas que entram na torcida é composta por homens, } \\
\text { na faixa etária de } 14 \text { a } 22 \text { anos, oriundos da classe média da cidade. } \\
\text { - A torcida realiza ações sociais como doação de sangue, campanhas } \\
\text { de agasalho e cobertores, além de distribuição de ovos de páscoa e } \\
\text { de cestas natalinas. } \\
\text { - A torcida possui um programa de televisão online chamado "TV } \\
\text { Mancha", vinculado ao AllTV }\end{array}$ \\
\hline
\end{tabular}


conclusão

\begin{tabular}{|c|c|c|}
\hline$\stackrel{8}{\rightleftarrows}$ & Conjuntura histórica & Informações biográficas \\
\hline 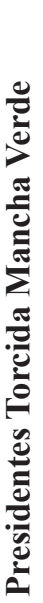 & & $\begin{array}{l}\text { - Os presidentes da Torcida Mancha Verde foram: } \\
\text { - Dorival Menezes (83/84) } \\
\text { - Nelson Ferraz da Silva Barros (Atibaia) (85/86) } \\
\text { - Cléo Sóstenes Dantas Silva (87/88) } \\
\text { - Moacir Bianchi (89/90) } \\
\text { - Ricardo Raphael Rodrigues (91/92) } \\
\text { - Paulo Serdan (93 a 98) } \\
\text { - Robertinho (98 a 2000) } \\
\text { - Jânio (2001 a 2004) } \\
\text { - Angelo (2004) } \\
\text { - Luizinho (2005) } \\
\text { - Jânio (2006 a 2008) } \\
\text { - André Guerra (2008 a 2012) } \\
\text { - Marcos Ferreira (desde 2012) }\end{array}$ \\
\hline 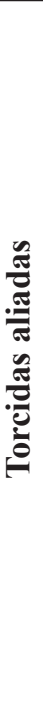 & & $\begin{array}{l}\text { - A Mancha Alviverde faz parte da união de torcidas chamada "Dedo } \\
\text { pro Alto", junto com as torcidas Força Jovem do Vasco da Gama } \\
\text { e Galoucura do Atlético Mineiro. Outras torcidas que mantém boa } \\
\text { relação com essa união são: } \\
\text { - Ira Jovem do Vasco } \\
\text { - Império Verde do Coritiba } \\
\text { - Mancha Azul do Avaí } \\
\text { - Mancha Verde do Juventude } \\
\text { - Força Jovem do Goiás } \\
\text { - Bamor do Bahia } \\
\text { - Cearamor do Ceará Sporting Club } \\
\text { - Torcida Jovem do Grêmio } \\
\text { - Inferno Coral do Santa Cruz } \\
\text { - Garra Alvinegra do ABC de Natal } \\
\text { - Terror Bicolor do Paysandu } \\
\text { - Torcida Jovem do Botafogo } \\
\text { - Mancha Azul do CSA }\end{array}$ \\
\hline
\end{tabular}

Fonte: dados do autor.

O segundo Roteiro, cujo extrato acima reproduzimos, foi padronizado e adotado de maneira sistemática em todas as entrevistas. Ele trazia informações disponíveis sobre os representantes de torcida, nas mais variadas fontes (livros, revistas, jornais, sites, DVDs, etc.). Seu tamanho médio girou em torno de vinte e cinco laudas, mas variava, para mais ou para menos, conforme a projeção público-midiática do torcedor em questão.

O Roteiro afigura-se crucial para as entrevistas, pois serve de base para que os entrevistadores possam preparar-se e se sintam aptos a conduzi-la no dia da gravação, munidos de dados histórico-biográficos capazes de ir além do já previamente consabido. A demonstração do conhecimento prévio da vida do clube, da torcida e, eventualmente, do torcedor entrevistado, surte o efeito desejado em muitas entrevistas.

$O$ fato de os entrevistadores saberem determinados aspectos sobre o percurso da agremiação e mesmo do entrevistado favorece sobremaneira a valorização deste, no ato da concessão da entrevista. Muitos torcedores, de antemão cautelosos, vão-se soltando à medida que percebem estar diante de formuladores de questões com conhecimento de fato da sua trajetória, sem prejuízos de valor ou preconceitos previamente estabelecidos.

Ante o modo parcimonioso de fazer perguntas, ante o saber "ocultar-se e revelar-se dos 
entrevistadores", entrevistados como Adamastor (Independente), Paulo Serdan (Mancha Verde), Vila Maria (Camisa 12) e Dentinho (Gaviões da Fiel) por exemplo, deixaram-se nitidamente embalar pela natureza das perguntas e prolongaram sobremaneira o tempo para respostas entre o início (mais pontual) e o fim (mais dilatado) do depoimento.

\section{A GRAVAÇÃO, A TRANSCRIÇÃO E A EDIÇÃO DAS ENTREVISTAS}

Sem embargo, para articular com o item anterior, advirta-se de antemão que há um elemento imponderável no momento presencial da entrevista. Nenhum Roteiro, por mais completo que seja, é capaz de contornar essa imponderabilidade constitutiva da interface entrevistador/entrevistado (PORTELLI, 2010).

Se a preparação é um requisito fundamental e indispensável para o êxito de um bom depoimento, deve-se considerar a importância crucial da interação entre o que fala e o que escuta no ato mesmo do registro. Na mesma proporção, mencione-se a importância atribuída por um etnógrafo em campo, ao tratar da relação pesquisador/informante, com vistas a chegar a uma antropologia hermenêutica de seus nativos.

A historiadora Ângela de Castro Gomes aponta como especificidade da História Oral a resultante emocional de que é produto um documento derivado de entrevista:

“...os documentos orais produzidos através de entrevistas exigem do pesquisador um nível de envolvimento distinto. Ele participa neste caso de construção do documento-relato, não só na medida em que propõe questões como também na medida em que compartilha as emoções despertadas no entrevistado pela rememoração de sua vida. Aí reside, a meu ver, uma das grandes contribuições das entrevistas orais: elas obrigam o pesquisador a uma forte interação com seu objeto de estudo, enriquecendo-o com uma nova sensibilidade".

“... o valor fundamental de um depoimento oral não reside tanto na produção de informações novas e substantivas. Na verdade, quase sempre ocorre uma convergência básica com os dados e as interpretações contidas nos documentos escritos. A informação nova trazida pelo depoimento oral está na forma pela qual o relato dimensiona e faz emergirem os acontecimentos, dando contextualidade às opções tomadas e novas cores aos perfis de personagens muitas vezes conhecidas.” (GOMES, 1998, p. 8)

De posse do Roteiro, e ciente dos interstícios de toda relação dialógica contida numa entrevista de História Oral, passam-se às etapas seguintes, quais sejam, o agendamento e a gravação da entrevista, por meio de contato telefônico ou através de intermediários (clubes, amigos, parentes, jornalistas), situações irregulares que oscilaram de torcedor a torcedor, de torcida a torcida.

Conforme já mencionado acima, a gravação costumou ser feita no Auditório Armando Nogueira, nas dependências do Museu do Futebol. Este foi considerado o palco ideal para receber as lideranças e para a montagem dos equipamentos. À preparação do roteiro, às cautelas metodológicas, ao agendamento e à gravação, sucederam-se as etapas posteriores da entrevista, com a transcrição, a edição e a organização do material gravado.

A etapa final concerne à edição. Trata-se de fase assaz importante, em que os editores e supervisores tiveram a responsabilidade de transpor para a linguagem escrita elementos singulares da fala coloquial e da oralidade. A técnica da História Oral valoriza sobremaneira este momento, na medida em que esta passagem fixará no plano gráfico a experiência narrada pela voz e pela dicção do torcedor, dentre gírias, jargões, palavras de baixo calão e mesmo problemas crassos de concordância, em alguns casos.

Tem-se, assim, elementos de oralidade que conferem à fonte perscrutada o seu valor de uso, passível de ser agregado às metodologias da História contemporânea. Esta permite, pois, a incorporação de múltiplos atores e segmentos sociais, consoante princípios legítimos da historiografia na contemporaneidade.

\section{BIBLIOGRAFIA}

ALBERTI, Verena. Manual de história oral. Rio de Janeiro: Editora da FGV, 2002.

Ouvir contar: textos em história oral. Rio de Janeiro: Editora FGV, 2004.

ALMEIDA, Maria Isabel Mendes; EUGÊNIO, Fernando (Orgs.). Culturas jovens: novos mapas do afeto. Rio de Janeiro: Zahar, 2006. 
BROCCHI, Gabriel Moreira Monteiro. Do estádio do Pacaembu para a Arena Corinthians: etnografia de um processo de 'atualização'. São Paulo: Dissertação de Mestrado/Antropologia Social-USP, 2017.

BROMBERGER, Christian. "Du public et des supporters". In: Football, la bagatelle la plus sérieuse du monde. Paris: Bayard Éditions, 1998.

BUFORD, Bill. Entre os vândalos: a multidão e a sedução da violência. São Paulo: Companhia das Letras, 1992.

CHAUÍ, Marilena. “A memória: lembrança e identidade do eu”. In: Convite à filosofia. São Paulo: Editora Ática, 2000.

FERNANDES, Fernando Manuel Bessa. Campo de força: sociabilidade em uma torcida organizada de futebol. Rio de Janeiro: Dissertação de Mestrado em Antropologia / UFF, 2000 .

FERREIRA, Marieta de Moraes; AMADO, Janaína. (Orgs.). Usos e abusos da história oral. Rio de Janeiro: Editora Fundação Getúlio Vargas, 2002.

FLORES, Luís Felipe Baeta Neves. "Da construção do conceito de violência ". In: Revista Pesquisa de Campo. Rio de Janeiro: UERJ / Departamento Cultural, 1995, nº 2.

GOMES, Ângela de Castro (Org.). Velhos militantes depoimentos. Rio de Janeiro: Editora Zahar, 1998.

LE GOFF, Jacques. História e memória. Campinas: Ed. Unicamp, 2003.

MEIHY, José Sebe Bom. Manual de história oral. São Paulo: Loyola, 2000.

MONTEIRO, Rodrigo de Araújo. "Torcer, lutar, o inimigo massacrar - Raça Rubro-Negra!": uma etnografia sobre futebol, violência e masculinidade. Prefácio de Alba Zaluar. Rio de Janeiro: Editora Fundação Getúlio Vargas, 2003.

MURAD, Maurício. A violência no futebol: novas pesquisas, novas ideias, novas propostas. Rio de Janeiro: Benvirá, 2016.

ORTIZ, Renato. Trajetos e memórias. São Paulo: Brasiliense, 2010.

PORTELLI, Alessandro. Ensaios de história oral. São Paulo: Letra e Voz, 2010.

TOLEDO, Luiz Henrique. "Políticas da corporalidade: socialidade torcedora entre 1990-2010". In: HOLLANDA, B. B. de; MELO, V. A. de. A torcida brasileira. Rio de Janeiro: 7Letras, 2012.

VIANNA, Hermano (Org.). Galeras cariocas: territórios de conflitos e encontros culturais. Rio de Janeiro: Editora UFRJ, 1997. 